\title{
Study on hybrid reactive power compensation in low-voltage distribution system \\ WANG Guoyou ${ }^{1, a}$, ZHANG Xilin ${ }^{1, b}$
}

\author{
${ }^{1}$ State Grid Jilin Electric Power Company Limited Changchun Power Supply Company, Changchun, \\ Jilin Changchun 130021, China \\ azhenhaowang@126.com, b985222805@qq.com
}

\begin{abstract}
Keywords: Hybrid reactive power compensation; Dynamic compensation; TSC; D-STATCOM Abstract: In this paper, we first introduce the topology structure of TSC (thyristor switched capacitor) and D-STATCOM (static var generator), which is composed of a group of D-STATCOM of small capacity and multi group TSC. According to the characteristics of the two, a hybrid reactive power compensation device is designed. Studying on the best capacity ratio and control method of the two, the TSC module is used to compensate most of the inductive reactive power, while the remaining part of over or under compensation is compensated by D-STATCOM, so as to achieve accurate compensation of reactive power. It is identified by the simulation experiment of the hybrid reactive power compensation device based on MATLAB/SIMULINK that the design is feasible.
\end{abstract}

\section{Introduction}

Although TSC(Thyristor Switched Capacitors) has lower production costs, only graded reactive power compensation can be carried out ${ }^{[1-2]}$. However, it has low efficiency and control accuracy, and it may do harm to the power grid.

D-STATCOM (Distribution Static Var Compensation) can not only compensate reactive power constantly, but also work on keeping the voltage stable. What's more, it has fast response and no excess $\operatorname{loss}^{[3-4]}$. It has not been popularized just because of high cost and limited capacity. Combining the advantages and disadvantages of the two, a hybrid reactive power compensation device is constituted ${ }^{[5-8]}$. It consists of several groups of TSC with the same capacity and a group of small capacity of the D-STATCOM combination. The two complement each other to achieve a low cost, large capacity of the rapid compensation of reactive power. This paper focuses on the reactive power compensation device design, TSC and D-STATCOM capacity allocation and control method research, and carrys on a simulation analysis on the hybrid reactive power compensation device based on MATLAB/SIMULINK.

\section{System structure of the hybrid reactive power compensation device}

TSC compensates most of the inductive reactive power, and D-STATCOM is to compensate/offset the excess part of reactive power. The principle structure diagram is shown in Fig. 1. The device is parallelled in the power grid to compensate, constituted by each unit of TSC and D-STATCOM. It selects the appropriate capacity ratio to meet the needs of compensation. According to the information collected from the power grid, the central control module determines the compensation capacity of D-STATCOM and the amount of TSC put in or reduce by fast and accurate calculation. At the same time, it sends out a control signal to them to complete the investment and control. 


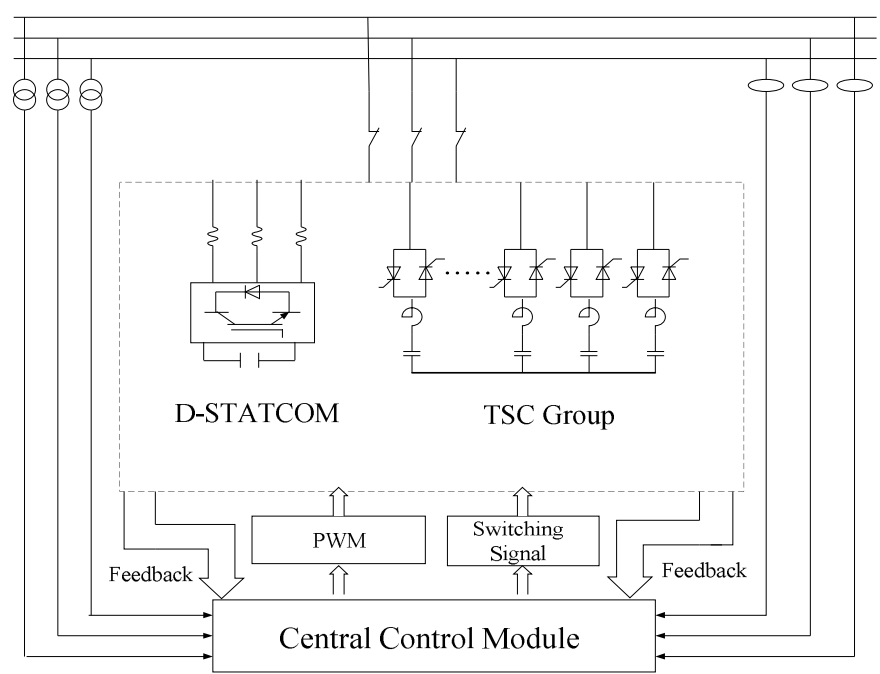

Fig. 1 Topology structure of the hybrid reactive power compensation device

\section{Optimal capacity ratio of D-STATCOM and TSC}

The ratio of compensation capacity of TSC and D-STATCOM hybrid system directly affects the whole system structure, cost and compensation effect. Therefore, we study on the optimal capacity ratio of TSC and D-STATCOM.

Based on the analysis of single phase equivalent circuit of hybrid reactive power compensation system, the sum of the total current of the hybrid reactive power compensation device is equal to the sum of the reactive current compensation of TSC and D-STATCOM after putting the capacitance in.

$$
I_{Q}=t I_{C}+I_{q S T A T}=t \omega U_{S} C+\frac{U_{S}}{2 R} \sin (2 \delta)
$$

The required reactive current compensation $\mathrm{I}_{\mathrm{QZ}}$ is provided.

$$
I_{Q Z}=\left(\left[\frac{I_{Q Z}}{I_{C}}\right]\right) I_{C}+\left(I_{Q Z}-\left(\left[\frac{I_{Q Z}}{I_{C}}\right]\right) I_{C}\right)=K I_{C}+\left(I_{Q Z}-K I_{C}\right)
$$

The amount of reactive power which D-STATCOM put out, the number of TSC groups and Q have the following relationships:

$$
Q_{1}\left\{\begin{array} { c } 
{ K , Q _ { \text { STAT } } \leq I _ { C } / 2 } \\
{ K + 1 , Q _ { \text { STAT } } \leq - I _ { C } / 2 }
\end{array} \text { or } \quad Q _ { 2 } \left\{\begin{array}{c}
K, Q_{\text {STAT }} \geq I_{C} / 2 \\
K+1, Q_{\text {STAT }} \geq-I_{C} / 2
\end{array}\right.\right.
$$

According to the formula (3), we find that, the value of the capacity of D-STATCOM is $\mid I_{S T A T}$ $\mid \geq\left(I_{C} / 2\right)$. Considering the analysis and cost of various situations, we take $\left|I_{S T A T}\right|=I_{C} / 2$, that is, the capacity of D-STATCOM can be half of the capacity of a single group of TSC. In this case, we can satisfy any demand within the scope of compensation of the device.

\section{Research on the control method}

The designed control method of the device in this paper is shown in Fig. 3, that is, when the capacity is configured as $I_{D S T M A X}=I_{C} / 2$, the hybrid compensation device can meet any value in the range of compensation capacity. When the number of TSC capacitor group which can be switched in hybrid dynamic reactive power compensator is $\mathrm{n}$, the total compensation capacity for TSC is $n I_{C}$. Since the D-STATCOM can not only absorb but emit reactive power, when all the TSC capacitors are put in and D-STATCOM delivered most of the capacitive reactive current, the hybrid reactive power compensator can put out the maximum capacitive reactive current $I_{M A X}$ $=I_{\text {TSCmax }}+I_{D S T \max }=(\mathrm{n}+1 / 2) I_{C}$. Only when the D-STATCOM inductive the maximum reactive current, 
the hybrid reactive power compensation device can inductive the maximum current, that is, $I_{L M A X}=$ $-I_{C} / 2$ According to the above analysis, the reactive current compensated by the system can change continuously in the range of $-I_{C} / 2 \leq I \leq(\mathrm{n}+1 / 2) I_{C}$, realizing the purpose of large capacity continuous compensation of the hybrid compensation device. $I_{C}$ is on behalf of the output reactive power compensation current of a single group of TSC. The range of the output reactive current of DSTATCOM is $-I_{C} / 2 \leq I_{D S T M A X} \leq I_{C} / 2$.

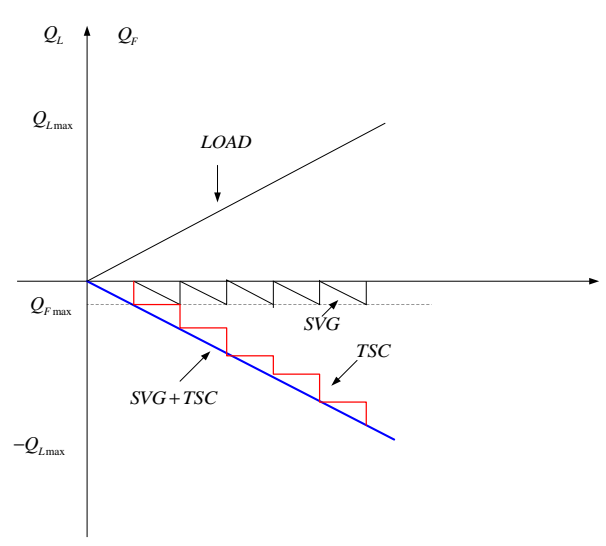

Fig. 2 Principle of the control method of the device

\section{Simulation experiment of the reactive power compensation device}

The parameters of the main circuit elements of the hybrid reactive power compensation device in SIMULINK system are shown in Table 1.

Table 1 Parameters of the simulation experiment

\begin{tabular}{c|c}
\hline Variable & Parameter \\
\hline Supply voltage rms ( kV $)$ & 66 \\
Frequency $(\mathrm{Hz})$ & 50 \\
Active power of load ( W ) & $18 \times 10^{6}$ \\
Reactive power of load ( Var ) & $18 \times 10^{6}$ \\
Single set capacity of TSC ( Mvar ) $\times$ Group number & $6 \times 3$ \\
Inductance $L(\mathrm{mH})$ & 0.1 \\
Capacitance $C_{\mathrm{T}}(\mathrm{F})$ & $5 \times 10^{-4}$ \\
Thyristor voltage ( KV ) & 40 \\
D-STATCOM capacity ( Mvar ) & 3 \\
IGBT driving voltage ( V ) & 5 \\
DC capacitor $C_{\mathrm{D}}(\mu \mathrm{F})$ & 2200 \\
DC capacitor voltage $U_{\mathrm{DC}}(\mathrm{V})$ & 1700 \\
Voltage loop PI parameters & $K_{\mathrm{Pv}}=5, K_{\mathrm{Iv}}=1000$ \\
\hline
\end{tabular}

\section{The analysis of simulation results}

During the simulation, a set of inductive load is suddenly put in in $0.1 \mathrm{~s}$. The waveform of threephase voltage $U \mathrm{a}, U \mathrm{~b}, U \mathrm{c}$ is shown in Fig. 4(a). According to the reactive power change detected by the system, the reactive power compensation of the system is carried out by D-STATCOM, and the waveform of the three-phase voltage is shown in Fig. 4(b). According to the reactive power change 
detected by the system, the reactive power compensation of the system is carried out by TSC, and the waveform of the three-phase voltage is shown in Fig. 4(c). The system is compensated by a hybrid reactive power compensation device, and its voltage waveform of access point is shown in Fig. 4(d). Through the above analysis we can find the following points. In Fig. 4(a), due to the sudden input of inductive load, the system voltage amplitude decreased. In Fig. 4(b), the reactive power detected by the system, the system automatically sends out the signal to the D-STATCOM, but because of the limited capacity of the D-STATCOM, it does not achieve the desired effect. Even if D-STATCOM injects the maximum current into the power grid, the voltage of reactive power is still falling down owing to lack of the reactive power. In Fig. 4(c), the system automatically sends out the signal to the TSC to make the reactive power compensation to the system after detecting the reactive power. But because TSC has the characteristics of step compensation, the over compensation or under compensation is often occurred, which can not achieve the desired effect. In Fig. 4(d), the system detect the reactive power change, and calculate the amount of change, then the hybrid reactive power compensation device is put into operation. The system respectively put out control signals to TSC and D-STATCOM. The TSC compensates the large capacity of reactive power, while the D-STATCOM offsets the redundant reactive power. The two mutual echo, and the three-phase voltage are quickly restored to the voltage of initial value. It can be seen from the comparison of the above three cases that the compensation effect of the hybrid reactive power compensation device is the best.

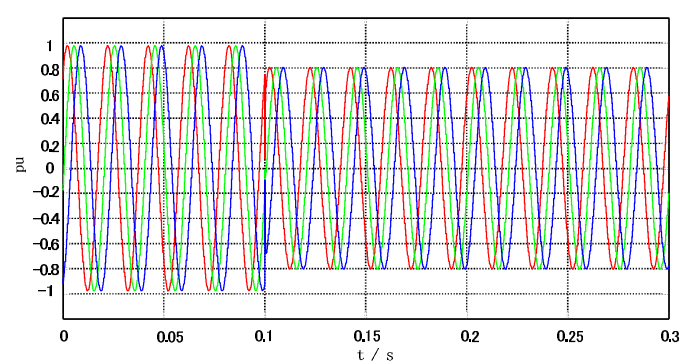

(a) The voltage waveform after the inductive

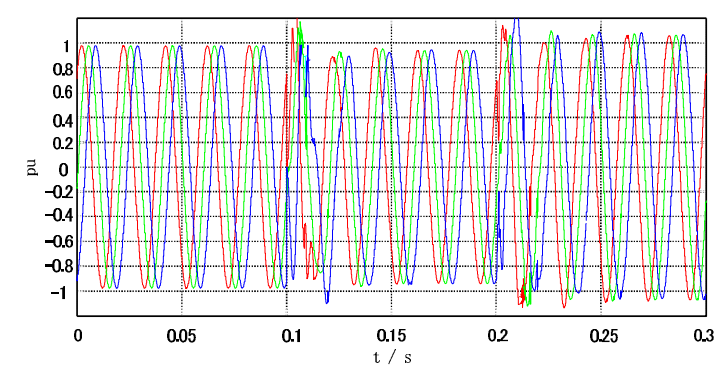

(c) The voltage waveform of inputting the

TSC compensation device alone

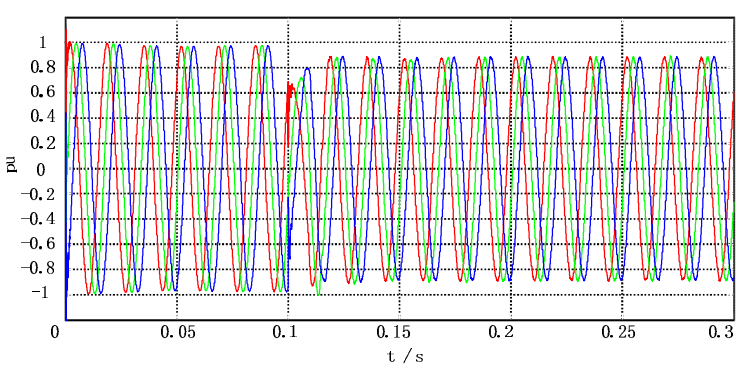

(b) The voltage waveform of inputting the D-STATCOM compensation device alone

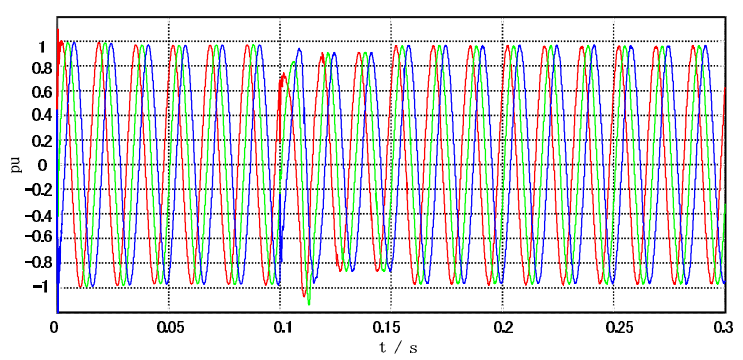

(d) The voltage waveform of inputting the hybrid reactive power compensation device

Fig. 3 The waveforms of the simulation experiment

\section{Conclusion}

The designed hybrid reactive power compensation device for low voltage distribution network are able to make a reasonable distribution of reactive power and control the device accurately. The TSC module of the system compensates most of the inductive reactive power, while the residual part is compensated by the D-STATCOM, and the results are verified by the simulation experiment. 


\section{References}

[1] YU Hong, CHEN Qiaofu, XIE Bingruo, et al. Novel practical device for reactive-power compensation and harmonic suppression[J]. Electrotechnical Application, 2007, 26(6): 21-25.

[2] YAO Shun, LUO An, FAN Ruixiang, et al. Software \& hard ware design of intelligent var compensation system for low-voltage distribution system[J]. Electric Power Automation Equipment, 2006, 26(12): 90-93.

[3] MA Ruijun, WANG Huiyun, CHANG Xianrong, et al. Novel Detection Method for DSTATCOM with High Compensation Precision[J]. Proceedings of the CSU-EPSA, 2015, 27(10): 62-68.

[4] WEI Chengzhi, SU Jiehe, WEN An, et al. Reactive voltage coordinated control for distribution network with DSTATCOMs and DGs[J]. Automation of Electric Power Systems, 2015, 39(9): 132-137,163.

[5] XU Guilin, LUO An, XIAO Huagen. Fuzzy adaptive passivity-based control of DSTATCOM[J]. Power Electronics, 2013, 47(2): 4-6.

[6] YANG Jiaqiang, CHEN Shilan, ZHU Jie, et al. Control strategy designing of hybrid compensator based on APF and TSC[J]. Electric Machines and Control, 2014, 18(1): 11-18.

[7] NI Changmao, LIU Zhenxing. Hybrid reactive power compensation and filtering device based on dual tuning filter and TSC[J]. Electric Power Automation Equipment, 2012, 32(7): 124-128.

[8] WANG Liguo, XU Dianguo, MIAO Lijie, et al. A modeling analysis of passive power device and influence of parameter perturbation on power system $[\mathrm{J}]$. Proceedings of the CSEE, 2005,25(10): 70-74. 